\title{
Preparation of superhydrophobic silver nano coatings with feather-like structures by electroless galvanic deposition
}

\author{
FENG XiaoJuan ${ }^{1}$, SHI YanLong ${ }^{1 *}$, WANG YongSheng ${ }^{1}$, YUE GuoRen $^{1} \&$ YANG Wu $^{2}$ \\ ${ }^{1}$ College of Chemistry and Chemical Engineering, Key Laboratory of Hexi Corridor Resources Utilization of Gansu Universities, Hexi University, \\ Zhangye 734000, China; \\ ${ }^{2}$ College of Chemistry and Chemical Engineering, Key Laboratory of Eco-Environmental Related Polymer Materials of Ministry of Education, \\ Northwest Normal University, Lanzhou 730070, China
}

Received November 18, 2012; accepted November 30, 2012; published online March 22, 2013

\begin{abstract}
Superhydrophobic silver nanocoatings with feather-like morphology are fabricated on copper substrates by electroless galvanic deposition. The coating exhibit superhydrophobicity with a contact angle of $156.4^{\circ}$ and glide angle of $4^{\circ}$ without any further surface modification. Scanning electron microscope (SEM), X-ray diffraction (XRD) and contact angle measurements are used to investigate the morphology, crystal structure and superhydrophobicity, respectively, of the coatings. The coatings exhibit high thermal stability; their water contact angle did not change when the coatings were heated to $200^{\circ} \mathrm{C}$ for $2 \mathrm{~h}$. The mechanism of superhydrophobicity of the silver coating is discussed based on the work of Amirfazli, Wenzel and Cassie.
\end{abstract}

silver nano coating, superhydrophobicity, contact angle, composite interface

Citation: Feng X J, Shi Y L, Wang Y S, et al. Preparation of superhydrophobic silver nano coatings with feather-like structures by electroless galvanic deposition. Chin Sci Bull, 2013, 58: 1887-1891, doi: 10.1007/S11434-013-5755-9

The wettability of a solid surface is a very important interfacial behavior. Recently, superhydrophobic surfaces have attracted great interest because of their potential for application in the fields of water repellency, antisticking, self-cleaning and antifouling [1-8]. Wettability is normally characterized by measurement of the contact angle (CA) of a surface. Generally, surfaces with water contact angles larger than $150^{\circ}$ and slide angles lower than $10^{\circ}$ are called superhydrophobic $[9,10]$.

In nature, many plants and insects have evolved to exhibit perfect superhydrophobicity; for example, the lotus leaf [7,11], water-strider legs [12], the hind wings of the waterman [13], cicadae [14], termite wings and backs of beetles $[15,16]$. Research has revealed that the dual-scale hierarchical structures of natural surfaces can not only ensure practical superhydrophobic performance but also provide mechanical durability [17]. Inspired by the fascinating functions of such structures in nature $[18,19]$, two kinds of approaches have

*Corresponding author (email: yanlongshi@yahoo.cn) been proposed to artificially fabricate superhydrophobic surfaces. One is to create micro-/nanostructures on hydrophobic surfaces. Many techniques have been developed to generate rough solid surfaces, including crystallization control [20], phase separation [21,22], template synthesis [23,24], electrochemical deposition [25], and chemical vapor deposition [26]. The other approach is to chemically modify micro-/nanostructured surfaces with materials with low surface free energy [7]. Such materials include fluoroalkylsilane [27], fluoropolymers [28], organic polymers [29], and alkylketene dimers [30]. However, most of the techniques described above require multiple steps, specific substrates, special equipment or harsh chemical treatment, which seriously hinder the practical application of superhydrophobic materials. In this paper, we present a simple method to fabricate large-area superhydrophobic silver coatings on unmodified copper substrate. The structure and superhydrophobicity of the silver coating can be controlled simply by adjusting the initial concentration of silver nitrate and reaction time. 


\section{Experimental}

\subsection{Fabrication of silver coatings on copper substrate}

Copper substrates with a size of $2.0 \mathrm{~cm} \times 2.0 \mathrm{~cm}$ were ultrasonically cleaned in ethanol for $1 \mathrm{~h}$. The substrates were rinsed with distilled water and air-dried at room temperature. The copper substrates were then vertically dipped into silver nitrate solution, held for a Specified period, removed and then heated at $70^{\circ} \mathrm{C}$ for $30 \mathrm{~min}$. Substrates were cooled befor subsequent measurement and characterization.

\subsection{Characterization}

Surface morphologies were observed by a scanning electron field-emission microscope (FE-SEM, Hitachi 4800, Japan). The crystal structure of silver powder pealed from the copper substrate were characterized using an X-ray diffractometer (XRD, D/MAX-2400, Rigaku, Japan) with $\mathrm{Cu} \mathrm{K} \alpha$ radiation. CAs were measured using a CA meter (DSA100, Krüss, Germany) at room temperature. Water droplets with a volume of $5 \mu \mathrm{L}$ were placed at five different positions for each sample. Images of water droplets were obtained using a digital camera.

\section{Results and discussion}

Silver coatings were deposited on copper substrate through the following galvanic exchange reaction:

$$
\mathrm{Cu}+2 \mathrm{Ag}^{+}=2 \mathrm{Ag}+\mathrm{Cu}^{2+}
$$

Surface morphologies of the as-prepared silver coatings were characterized by FE-SEM. Under the conditions of a low concentration of silver nitric $(0.00625 \mathrm{~mol} / \mathrm{L})$ and reaction time of $90 \mathrm{~s}$, silver coatings with various fractal-like structures formed on the copper substrate. The fractal-like structures were surrounded by tiny, almost indistinguishable voids, shown as Figure 1(a). The CA of water on this sample was $\sim 117.4^{\circ}$ (inset of Figure 1(a)). When the concentration of $\mathrm{Ag}^{+}$was increased to $0.025 \mathrm{~mol} / \mathrm{L}$, silver nanostructures with leaf-like or dendritic morphologies surrounded by coral-like clusters begun to form on the copper substrate. The CA of water on the silver nanoleaves increased to $154.4^{\circ}$ (shown in Figure 1(b) and its inset). The magnified image in Figure 1(c) shows the leaves contain vein-like structures. The length of the middle-sized veins in the silver nanoleaves are about $10 \mu \mathrm{m}$, while those of the lateral and minor veins are approximately 3-3.5 and $1 \mu \mathrm{m}$, respectively. The leaf-like veins are composed of spherical particles with diameters of 200-300 nm that were stringed together by a thread. The thickness of the silver nanocoating fabricated with an $\mathrm{Ag}^{+}$concentration of $0.025 \mathrm{~mol} / \mathrm{L}$ and reaction time of $90 \mathrm{~s}$ is about $35 \mu \mathrm{m}$ (Figure 1(d)). The composite leaflike structures with micro- and nanoscale components play an important role in the introduction of superhydrophobicity because of their effect on surface roughness. When the reaction time is increased from 90 to $150 \mathrm{~s}$ at a fixed silver concentration of $0.025 \mathrm{~mol} / \mathrm{L}$, the stability of the coating decreased, and its morphology varied from leaf- to featherlike (Figure 1(e)). The CA of water on the feather-like surface was about $154.5^{\circ}$. A digital photograph of a water droplet on the silver coating shown in Figure 1(e) is presented in Figure 1(f).

The above analysis reveals that both initial $\mathrm{Ag}^{+}$concentration and reaction time play important roles in the generation of superhydrophobic silver coating, because $\mathrm{Ag}^{+}$concentration and reaction time both affects the morphology and surface roughness of the coating. The silver nanocoatings formed with an $\mathrm{Ag}^{+}$concentration of $0.025 \mathrm{~mol} / \mathrm{L}$ and reaction time of 90-120 s possess suitable surface roughness to exhibit optimal superhydrophobicity, with a water $\mathrm{CA}$ of $154.4^{\circ}-156.4^{\circ}$ and slide angle of about $4^{\circ}$. The correlations between water $\mathrm{CA}$ and initial $\mathrm{Ag}^{+}$concentration and reaction time are shown in Figure 2(a) and (b).

Silver coatings with leaf-like structure were placed in oven for $2 \mathrm{~h}$ at $200^{\circ} \mathrm{C}$, and then cooled naturally. No apparent changes were observed in the $\mathrm{CA}$ of water, revealing that the silver coating with a leaf-like structure has high thermal stability. To test the dynamic behavior of water droplets on the optimal superhydrophobic silver coating, water droplets with a volum of $8 \mu \mathrm{L}$ were added dropwise onto the surface using a syringe. Interestingly, water droplets bounced up and down on the coating and then rolled off easily.

The surface morphology of the silver coating is related to both $\mathrm{Ag}^{+}$concentration and reaction time. According to ref. [31], the formation of silver nanocoatings follows a process of initial reduction, nucleation, adsorption, growth, braching, and further growth. As a result, the leaf-like nanostructures form through the attachment of silver particles and are controlled by the strength of reducing agent(s) in the system [32].

The leaf-like silver coating was scraped from the copper substrate and analyzed by XRD to determine its crystal structure. The CRD pattern in Figure 3 contains four peaks in the region of $35^{\circ}-80^{\circ}$ that can be indexed as the (111), (200), (220), and (311) planes of face-centered cubic Ag, consistent with JCPDS No. 4-783.

It is known that both surface morphology and surface free energy play important roles in the generation of superhydrophobicity. The mechanism of the transition from hydrophobicity to superhydrophobicity can be described based on the reports of Amirfazli groups [33,34], Wenzel [35] and Cassie et al. [36]. Water droplets on a silver nanocoating with low roughness form a noncomposite state (Wenzel state) where the droplets fill the asperities in the surface through the $3 \mathrm{D}$ capillary effect. CA and surface roughness increased as reaction time and $\mathrm{Ag}^{+}$concentration increased, causing the state to change from noncomposite (Wenzel state) to 

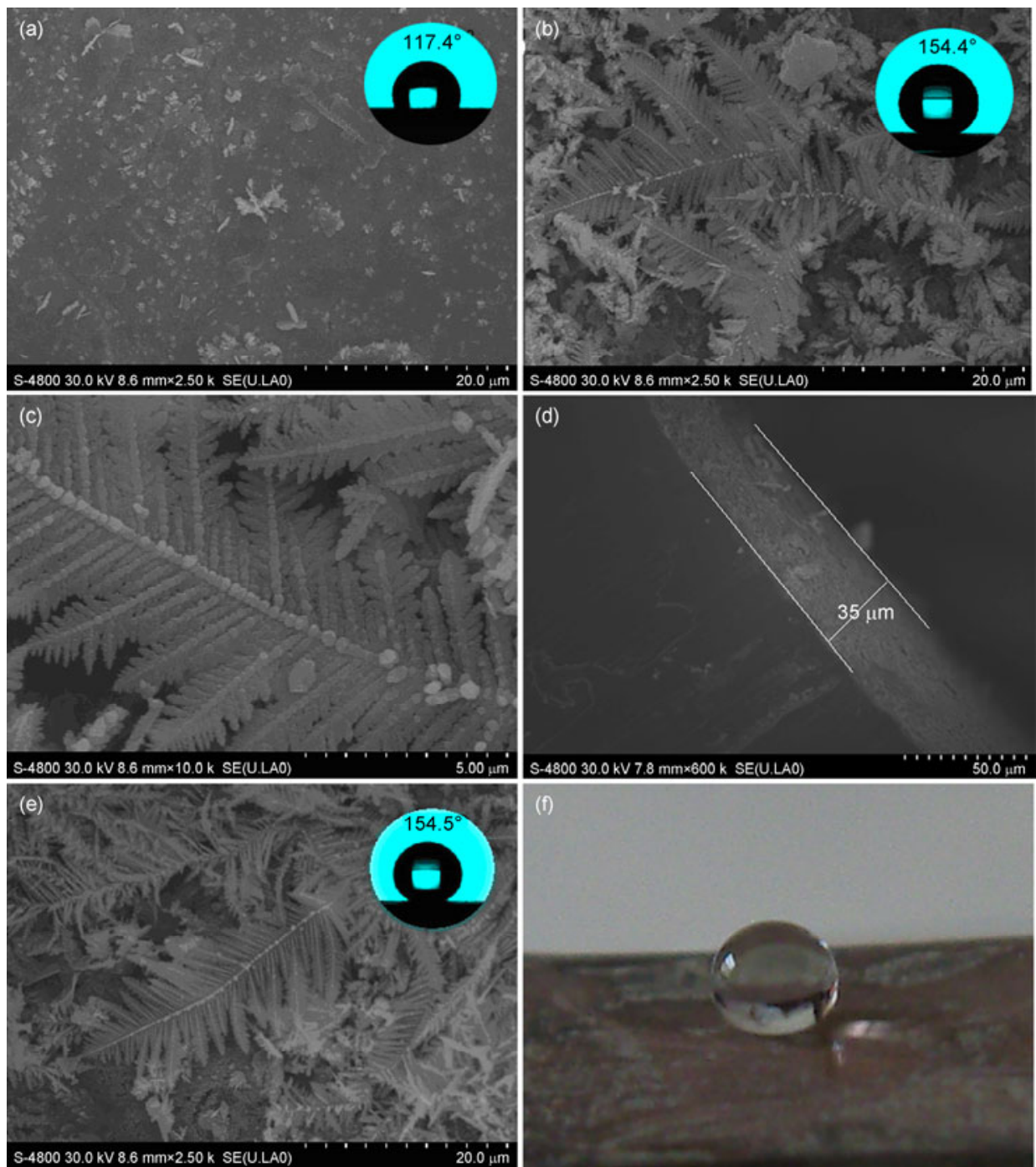

Figure 1 (Color online) SEM images of Ag coatings deposited on copper substrates by galvanic exchange reaction. ((a), (b)) Images of samples fabricated from aqueous solutions with initial $\mathrm{Ag}^{+}$concentration of $0.00625,0.025 \mathrm{~mol} / \mathrm{L}$ and reaction time of $90 \mathrm{~s}$, respectively; (c) magnification of Figure 1(b); (d) cross-sectional image of the sample fabricated with an initial $\mathrm{Ag}^{+}$concentration of $0.025 \mathrm{~mol} / \mathrm{L}$ and reaction time of $90 \mathrm{~s}$; (e) sample fabricated with an initial $\mathrm{Ag}^{+}$concentration of $0.025 \mathrm{~mol} / \mathrm{L}$ and reaction time of $150 \mathrm{~s}$; (f) digital photograph of water on the Ag coating shown in Figure 1(e). Insets are the optical images of water droplets on the surfaces of corresponding silver coatings.
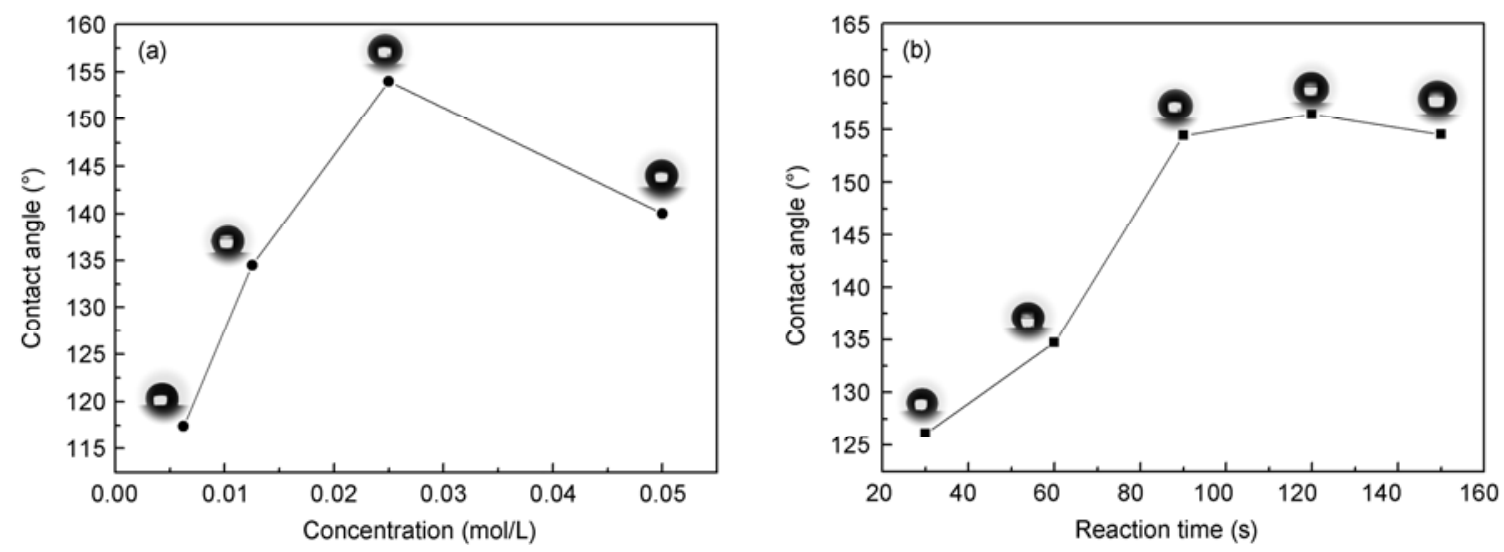

Figure 2 Variation of the $\mathrm{CA}$ of water with the concentration of silver nitrate at fixed reaction time of $90 \mathrm{~s}(\mathrm{a})$, and reaction time at fixed initial $\mathrm{Ag}^{+}$concentration of $0.025 \mathrm{~mol} / \mathrm{L}$ (b). 


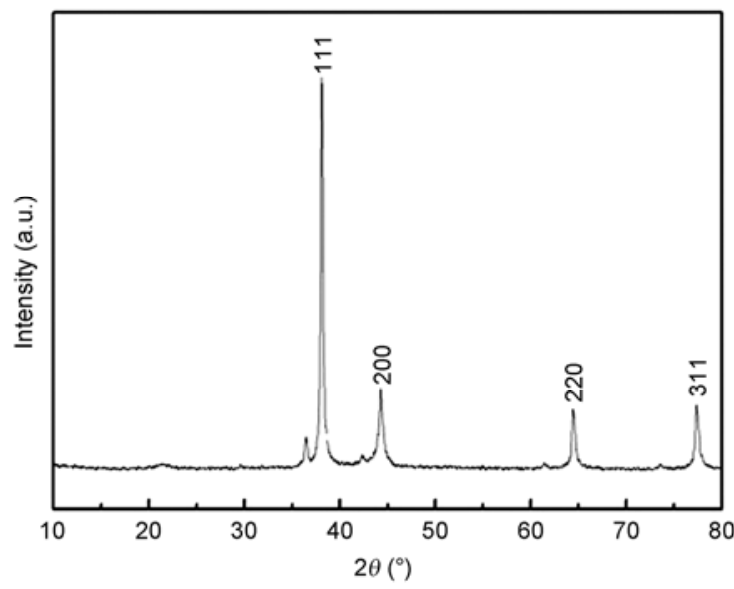

Figure 3 XRD pattern of the silver coating scraped from copper substrate.
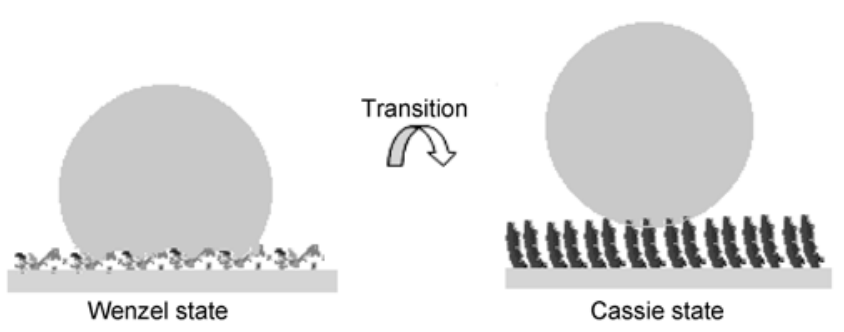

Figure 4 Transition from Wenzel state (wet contact between the liquid and rough substrate) to the Cassie state (non-wet contact between the liquid and rough substrate).

composite (Cassie state). In the composite state, CA and glide angles do not depend on surface roughness but are dominated by heterogeneity in the solid surface. As a result, water droplets do not fill the grooves, and remain stable because of the trapped air beneath them. Water droplets then began to roll off when the surface was tilted slightly, indicating the coating was superhydrophobic. The transition from the Wenzel to Cassie state is shown in Figure 4.

\section{Conclusions}

A simple technique to fabricate superhydrophobic silver coatings on copper substrate has been demonstrated. The $\mathrm{CA}$ of water on the silver coating could be increased to $156.4^{\circ}$ using $0.025 \mathrm{~mol} / \mathrm{L}$ silver nitrate and reaction time of $120 \mathrm{~s}$ without any further surface modification. Water droplets did not readily stick to the coating, and begun to roll off when the surface was tilted slightly. Superhydrophobicity is induced because of the hierarchical structures of these silver nanocoatings.

This work was supported by the Key Laboratory of Hexi Corridor Resources Utilization of Gansu Universities (ZX1101). Thanks Mr David for his assistance in the writing of the paper.
1 Mumm F, Van Helvoort A T J, Sikorski P. An easy route to superhydrophobic copper based droplet microfluidic systems. ACS Nano, 2009, 3: 2647-2652

2 Parkin I P, Palgrave R G. Self-cleaning coatings. J Mater Chem, 2005, 15: 1689-1695

3 Sun T L, Feng L, Gao X F, et al. Bioinspired surfaces with special wettability. Acc Chem Res, 2005, 38: 644-652

4 Xu Q F, Wang J N. A superhydrophobic coating on aluminium foil with an anti-corrosive property. New J Chem, 2009, 33: 734-738

5 Tuteja A, Choi W, Ma M L, et al. Designing superoleophobic surfaces. Science, 2007, 318: 1618-1622

6 Erbil H Y, Demirel A L, Avci Y, et al. Transformation of a simple plastic into a super-hydrophobic surface. Science, 2003, 299: 13771380

7 Feng L, Li S, Li Y, et al. Super-hydrophobic surfaces: From natural to artificial. Adv Mater, 2002, 14: 1857-1860

8 Nakajima A, Hashimoto K, Watanabe T. Recent studies on super-hydrophobic films. Mon Chem, 2001, 132: 31-41

9 Oner D, McCarthy T J. Ultrahydrophobic surfaces. Effect of topography length scales on wettability. Langmuir, 2000, 16: 7777-7782

10 Cao L, Price T P, Weiss M, et al. Super water- and oil-repellent surfaces on intrinsically hydrophilic and oleophilic porous silicon films. Langmuir, 2008, 24: 1640-1643

11 Barthlott W, Neinhuis C. Purity of the sacred lotus, or escape from contamination in biological surfaces. Planta, 1997, 202: 1-8

12 Gao X F, Jiang L. Water-repellent legs of water striders. Nature, 2004, 432: 36

13 Wang Y S, Shi Y L, Feng X J, et al. Investigation of superhydrophobicity on water boatman's hind wings (in Chinese). Chin Sci Bull (Chin Ver), 2012, 57: 1227-1230

14 Lee W, Jin M K, Yoo W C, et al. Nanostructuring of a polymeric substrate with well-defined nanometer-scale topography and tailored surface wettability. Langmuir, 2004, 20: 7665-7669

15 Andrew R P, Chris R L. Water capture by a desert beetle. Nature, 2001, 414: 33-34

16 Watson G S, Cribb B W, Watson J A. How micro/nanoarchitecture facilitates anti-Wetting: An elegant hierarchical design on the termite wing. ACS Nano, 2010, 4: 129-136

17 Li W, Amirfazhi A. Hierarchical structures for natural superhydrophobic surfaces. Soft Matter, 2008, 4: 462-466

18 Liu K S, Yao X, Jiang L. Recent developments in bio-inspired special wettability. Chem Soc Rev, 2010, 39: 3240-3255

19 Liu K S, Jiang L. Bio-inspired self-cleaning surfaces. Ann Rev Mater Res, 2012, 42: 231-263

20 Shibuichi S, Onda T, Satoh N, et al. Super-water-repellent fractal surfaces. Langmuir, 1996, 12: 2125-2127

21 Xie Q D, Fan G Q, Zhao N, et al. Facile creation of a bionic superhydrophobic block copolymer surface. Adv Mater, 2004, 16: 18301833

22 Han J T, Lee D H, Ryu C Y, et al. Fabrication of superhydrophobic surface from a supramolecular. Organosilane with quadruple hydrogen bonding. J Am Chem Soc, 2004, 126: 4796-4797

23 Sun M H, Luo C X, Xu L P, et al. Artificial lotus leaf by nanocasting. Langmuir, 2005, 21: 8978-8981

24 Feng L, Song Y L, Zhai J, et al. Creation of super-hydrophobic surface from amphiphilic polymer. Angew Chem Int Ed, 2003, 42: 800-802

25 Shi F, Wang Z Q, Zhang X, et al. Combining layer-by-layer assembly with electrodeposition of silver aggregates for fabricating superhydrophobic surfaces. Adv Mater, 2005, 17: 1005-1009

26 Lau K K S, Bico J, Teo K B K, et al. Superhydrophobic carbon nanotube forests. Nano Lett, 2003, 3: 1701-1705

27 Nakajima A, Fujishima A, Hashimoto K, et al. Preparation of transparent superhydrophobic boehmite and silica films by sublimation of aluminum acetylacetonate. Adv Mater, 1999, 11: 1365-1368

28 Morra M, Occhiello E, Garbassi F. Contact angle hysteresis in oxygen plasma treated poly(tetrafluoroethylene). Langmuir, 1989, 5: 872876

29 Youngblood J P, McCarthy T J. Ultrahydrophobic polymer surfaces 
prepared by simultaneous ablation of polypropylene and sputtering of poly(tetrafluoroethylene) using radio frequency plasma. Macromolecules, 1999, 32: 6800-6806

30 Shibuichi S, Onda T, Satoh N, et al. Super water-repellent surfaces resulting from fractal surfaces. J Phys Chem, 1996, 100: 1951219517

$31 \mathrm{Xu} \mathrm{X} \mathrm{H,} \mathrm{Zhang} \mathrm{Z} \mathrm{Z,} \mathrm{Yang} \mathrm{J.} \mathrm{Fabrication} \mathrm{of} \mathrm{biomimetic} \mathrm{superhydro-}$ phobic surface on engineering materials by a simple electroless galvanic deposition method. Langmuir, 2010, 26: 3654-3658

32 Mdluli P S, Revaprasadu N. Time dependant evolution of silver nanodendrites. Mater Lett, 2009, 63: 447-450

33 Li W, Amirfazli A. Microtextured superhydrophobic surfaces: A thermodynamic analysis. Adv Colloid Interface Sci, 2007, 132: 51-68

$34 \mathrm{Li} \mathrm{W}$, Amirfazli A. A thermodynamic approach for determining the contact angle hysteresis for superhydrophobic surfaces. J Colloid Interface Sci, 2005, 292: 195-201

35 Wenzel R N. Resistance of solid surfaces to wetting by water. Ind Eng Chem, 1936, 28: 988-994

36 Cassie A B D, Trans S B. Wettability of porous surfaces. Faraday Soc, 1944, 40: 546-551

Open Access This article is distributed under the terms of the Creative Commons Attribution License which permits any use, distribution, and reproduction in any medium, provided the original author(s) and source are credited. 